\title{
ASSESSING INDUSTRIAL ENGINEERING COURSES USING BENCHMARK, FACULTY EXPERIENCE AND FE REQUIREMENTS
}

\author{
Said Ali Hassan El-Quliti ${ }^{1 *}$ and Neyara Radwan ${ }^{2}$ \\ ${ }^{1}$ Prof., Department of Industrial Engineering, King Abdulaziz University, \\ Saudi Arabia, saalquliti@kau.edu.sa \\ ${ }^{2}$ Asst. Prof., Department of Industrial Engineering, , King Abdulaziz University, Saudi Arabia, \\ nrhassan@kau.edu.sa., and asst. Prof., Mechanical Department, Faculty of Engineering, Suez \\ Canal University, Egypt. \\ ${ }^{*}$ Corresponding author
}

\begin{abstract}
Faculty of Engineering at King Abdulaziz University plans to redesign its undergraduate courses, which is required for students in 14 different programs. These courses have an annual enrolment of about 2,500 students each year. The Operations Research Teaching Area in the Department of Industrial Engineering will be presented as a case study. This area involves two core and three elective courses.

The course redesign involves preparing students for the Fundamentals of Engineering (FE) Exam requirements while coping with the best worldwide practices as benchmark. The FE Exam is a computerbased test (CBT). It is closed book with an electronic reference. Examinees have 6 hours to complete the exam, which contains multiple-choice questions. The 6-hour time also includes a tutorial and an optional scheduled break. The exam session is administered in the following seven disciplines: Chemical, Civil, Electrical and Computer, Environmental, Industrial and Systems, Mechanical, and Other Disciplines. The top ten USA Universities in Industrial/Manufacturing Engineering are used as a benchmark to reliably lead to the desired courses redesign results. Moreover, faculty experience is also utilized to enhance the process.
\end{abstract}

Keywords: Industrial Engineering; Course design; Best practices; Benchmark; Fundamental Engineering.

\section{INTRODUCTION}

The typical study program for B.Sc. students in the Department of Industrial Engineering (IE) in King Abdulaziz University (KAU) is distributed over 10 semesters. The program offers a 5-year study program leading to a Bachelor of Science degree (B.Sc.) in Industrial Engineering. The program provides graduates with strong basic engineering knowledge, professional skills, effective proficiency, ability to work in teams and appreciation of the ethical, social and global issues required for engineers of the future.

The IE program covers five important areas of the industry: 
Operations Research, Information Systems, Stochastic Processes, Human Factors Engineering, and Engineering Management.

Figure 1 illustrates the current situation for the courses and contents is considered, and then the criteria for the assessment process will be based on the criteria of best practices, Fundamental Engineering Exam requirements, Market needs and accreditation requirements. The scope of this research will consider only the first two criteria to assess courses in the Operations Research Group only, while the other two criteria and other courses will be considered in upcoming researches.

Best practice is a noun that means "a well-defined procedure that is known to produce near-optimum results". A method or technique that has consistently shown results superior to those achieved with other means, and that is used as a benchmark. Best practices can be based on self-assessment or benchmarking (Bogan and English, 1994). Benchmarks may be drawn from a firm's own experience, from the experience of other firms in the industry, or from legal requirements such as environmental regulations. The top 10 U.S. universities practices will be used as a benchmark for the courses and course Syllabi assessment for the Department of Industrial Engineering and mainly for the Operations Research Group.

The Fundamentals of Engineering (FE) exam is typically the first step in the process leading to the P.E. license. The PE exam tests your ability to practice competently in a particular engineering discipline. It is designed for engineers who have gained at least four years' post-college work experience in their chosen engineering discipline. FE is designed for recent graduates and students who are close to finishing an undergraduate engineering degree. The FE is a computer-based exam that is administered year-round at NCEES-approved Pearson test centers, NCEES website (2016).

Teaching and learning are supported by a range of staff, including teachers, technicians, visiting experts, librarians, learning support staff, computer support staff and postgraduate students, who have received training appropriate to their role. In addition to the initial teaching qualifications of staff, there is a continuous enhancing of the skills for all staff that support learning, such schemes enable staff to build on their initial teaching qualifications and add value to their roles. Improving the experience in teaching and learning is accomplished with sources for dialogue and methods of feedback such as: self-dialogue through a teaching log, solicit feedback from students, classroom assessment techniques, dialogue with faculty, dialogue with peers, and seek outside consultation.

The second section will review the most related published works in the field related to that of the current paper. The third section will give an overview of the Department of Industrial Engineering at King Abdulaziz University. The fourth section will demonstrate features of the top ten Industrial Engineering U.S. Universities used as benchmark. The fifth section gives an overview of the Fundamental of Engineering (FE) Exam. The sixth section introduces the faculty experience. The seventh (last) section presents the conclusions and points for future researches.

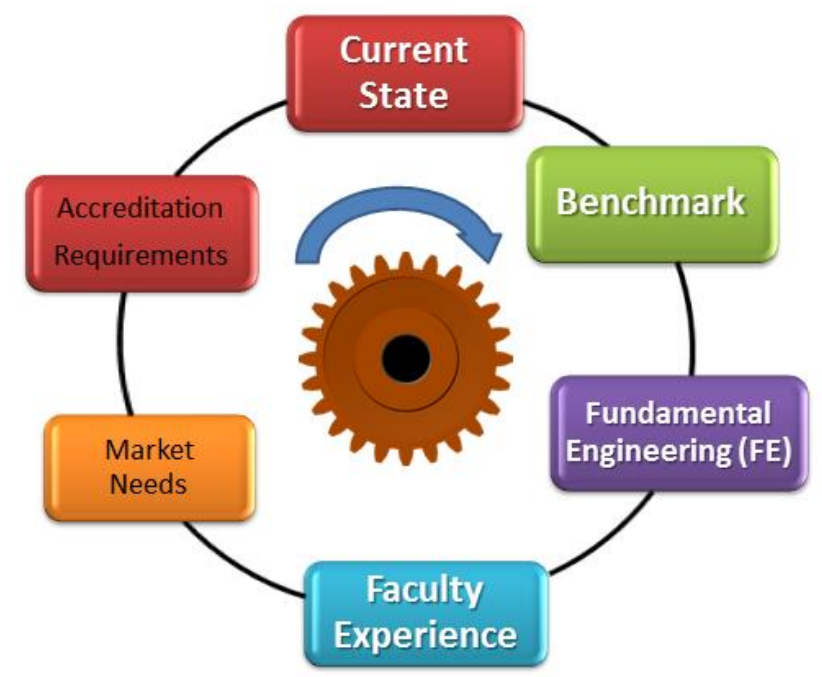

Figure 1: Criteria used for the assessment of current situation. 


\section{LITERATURE REVIEW}

Many articles and projects are performed addressing enhancing teaching and learning, learning objectives and learning outcomes, course redesign models, curriculum and course development and syllabus design. None of them include assessing using benchmark with the top Universities, the Fundamental Engineering Exam (FE) and the Faculty Experience for Industrial Engineering specialization.

Twigg (2015) states that many colleges and universities are discovering exciting new ways of using information technology to enhance teaching and learning and to extend access to new populations of students. The National Center for Academic Transformation (NCAT) has proven that it is possible to improve quality and reduce cost in higher education using information technology. Course redesign is the process of redesigning whole courses (rather than individual classes or sections) to achieve better learning outcomes at a lower cost by taking advantage of the capabilities of information technology. Course redesign is not just about putting courses online. Of the 156 completed projects, $72 \%$ improved student learning outcomes; $28 \%$ showed learning equivalent to traditional formats. Of the 156 completed projects, 153 reduced their costs by $34 \%$ on average (ranging from $4 \%$ to $81 \%$ ). The key quality improving strategies are: To move students from passive note-taking to active learning, Interactive tutorials and exercises, Continuous assessment and feedback, Increased interaction among students, On-demand support, and Monitoring and intervention. The key cost reduction techniques are: Online tutorials, automated assessment, Course management systems, Shared resources and Staffing substitutions. Cusson (2015) defines Learning Objective as Statements that describe specific instructional goals containing verbs that are observable and measurable. He defines also Learning Outcome as Broad goals that describe what the learners are supposed to know and be able to do.

The National center for Academic Reformation (2016) summarizes the characteristics of the six course redesign models. These models are: The supplemental model retains the basic structure of the traditional course and a) supplements lectures and textbooks with technology-based, out-of-class activities, or b) also changes what goes on in the class by creating an active learning environment within a large lecture hall setting. The replacement model reduces the number of in-class meetings and a) replaces some in-class time with out-of-class, online, interactive learning activities, or b) also makes significant changes in remaining inclass meetings. The emporium model replaces lectures with a learning resource center model featuring interactive computer software and on-demand personalized assistance. The fully online model eliminates all in-class meetings and moves all learning experiences online, using Web-based, multi-media resources, commercial software, automatically evaluated assessments with guided feedback and alternative staffing models. The buffet model customizes the learning environment for each student based on background, learning preference, and academic/professional goals and offers students an assortment of individualized paths to reach the same learning outcomes. The Linked Workshop model provides developmental instruction by linking workshops that offer students just-in-time supplemental academic support to core college-level courses. The paper gives also a full description of the six models with examples from the projects follows.

Another paper written by Ariovich and Walker (2015) presents findings from the assessment of course redesign by focusing on the case of developmental math at a large community college. The college adopted modularization, a common course redesign method in which concepts are disaggregated into modules and delivered through computer software. The study discusses faculty and student views and experiences in order to complement and help illuminate the results from the quantitative analysis. Using evidence from five focus groups, one with faculty and four with students, the paper provides insights on how to help faculty and students ease into their new roles and reshape those roles for an enhanced, more engaging, and more effective teaching and learning experience.

The definition of curriculum is complex because there are as many definitions as there are writers in the field. It can go anywhere along the range from a list of subjects for a course to the perception of the ultimate goal of education as a whole. What is required when referring to the term is "the grasp of the basic notions education involves as well as the structural organization every author states within this definition for the term curriculum" (Moreno, 2000: 11) Evidence of what mentioned before is the following listing of the same concept defined by different authors. Curriculum can be defined, as an educational program which states: The educational purpose of the program (the ends), The content teaching procedures and learning experience which will be necessary to achieve this purpose (the means) and means for assessing whether or not the educational ends have been achieved." (Richards, Platt and Platt 1993: 94) "Curriculum is a very general concept which involves consideration of the whole complex of philosophical, social and administrative factors which contribute to the planning of an educational program." (Nunan, 2000: 6).

"Curriculum theory encompasses philosophy and value systems; the main components of the curriculum: purposes, content, methodology and evaluation; and the process whereby curricula are developed, 
implemented and evaluated". (White, 1993: 19).

A course is "an integrated series of teaching-learning experiences, whose ultimate aim is to lead the learners to a particular state of knowledge". (Hutchinson and Waters 1996: 65) The distinction between a curriculum and a course is important because some of the areas of concern in curriculum development as: societal needs analysis, testing for placement purposes or program wide evaluation may be out of the hands of teachers who are developing courses (Richards, 2001).

A "Syllabus is essentially a statement of what should be taught, year by year-through language - syllabuses often also contain points about the method of teaching and the time to be taken" (Lee 1980:108). Another opinion is that that a "syllabus is a more detailed and operational statement of teaching and learning elements which translates the philosophy of the curriculum into a series of planned steps leading towards more narrowly defined objectives at each level" Dubin \& Olshtain, (1997: 28).

Syllabuses are more localized and are based on accounts and records of what actually happens at the classroom level. Given these definitions it is suggested that it seems helpful to define a curriculum and a syllabus as separate entities. To sum up it is possible to see syllabus design as part of course design, which in turn, forms part of the design of the curriculum as a whole.

McKimm (2003) stated that the word curriculum implies that one of the functions of a curriculum is to provide a template or design which enables learning to take place. Curricula usually define the learning that is expected to take place during a course or program of study in terms of knowledge, skills and attitudes, they should specify the main teaching, learning and assessment methods and provide an indication of the learning resources required to support the effective delivery of the course. A curriculum is more than a syllabus. A syllabus describes the content of a program and can be seen as one part of a curriculum. Most curricula are not developed from scratch and all operate within organizational and societal constraints.

Nulty, D. D., (2012) stated that successful learning and teaching depend on curricula that are transparent and effective in terms of goals, learning activities and assessment of learning outcomes. The following approaches and frameworks provide a starting point for developing an effective course curriculum.

Ornstein and Hunkins (2009) contend that curriculum development encompasses how a 'curriculum is planned, implemented and evaluated, as well as what people, processes and procedures are involved..'. Curriculum models help designers to systematically and transparently map out the rationale for the use of particular teaching, learning and assessment approaches. Ornstein and Hunkins (2009) suggest that although curriculum development models are technically useful, they often overlook the human aspect such as the personal attitudes, feelings, values involved in curriculum making. Therefore they are not a recipe and should not be a substitute for using your professional and personal judgment on what is a good approach to enhancing student learning.

A commonly described, maybe slight simplistic version of two polarized curriculum models are those referred to by many authors as the 'Product Model' and the 'Process Model'. Neary (2003) describes these as one which emphasizes 'plans and intentions (The Product Model) and one which emphasizes activities and effects' (The Process Model). The product model has been valuable in developing and communicating transparent outcomes to the student population and has moved emphasis away from lists of content. Recent literature in this area suggests that in using this model, care should be taken not to be overly prescriptive when writing learning outcomes (Gosling, 2009; Hussey\& Smith, 2008; Maher, 2004; Hussey \& Smith, 2003).

Woolcock, M. J.V., (2005) wrote a handbook that helps instructors to produce a syllabus which: Articulates specific aims and objectives for a course in their field, Identifies the relationship between course objectives, course content, and sequencing of material, Demonstrates how teaching effectiveness is related to student assessment and course objectives, States clearly defined mutual expectations and is clear and coherent.

The Center for teaching and Learning (2004) demonstrated that the final documentation of all this planning is, of course, the syllabus. The syllabus is the place where you can outline your learning goals for the course as well as your philosophy of teaching, your thematic framework for the term, and your breakdown of readings and assignments.

Since the syllabus is also an active contract with the students containing expectations for them as well as guidelines for succeeding in the course, include a section in the syllabus for course and university policies, such as a percentage breakdown of how graded assignments and class participation will be factored into a final grade, an attendance and absence policy, a late papers and revision policy, a scholar/ athlete make-up class and work policy, a disability disclosure policy, and a reminder of the parameters of the honour code.

The syllabus is a description and plan for a course and, if well written, may be a tool that improves student 
learning, facilitates faculty teaching, improves communications between faculty members about their courses, and assists with monitoring program quality, Habanek (2005) and Parkes et. al. (2003). Typically focused on the learner, well-written syllabi communicate to students what is expected to succeed in a course and what competencies must be mastered, Diamond (1998). As a general rule when writing or reviewing a syllabus, the syllabus contents should be so clear that they are easily understood by others who are not familiar with the course (those who have not taken the course). The syllabus should provide enough detail for students to understand what is expected of them and how the course proceeds. Optimally, the course syllabus should generate interest and motivate students to take responsibility to learn the contents of the course, Grunert (1997).

A publication written by Johnson (2006) is concerned with the best practices in syllabus writing. This article presents an overview of syllabus structure for faculty members who would like to develop and evaluate their syllabi. A brief overview about syllabus contents and a checklist is provided. The provided checklist includes the following items: General course information (Name, Term, Location, time and Prerequisites), Instructor information (Names, Office hours and contact information, Purpose of the course (purpose, goals, objectives), The learning environment (Facilities and teaching methods, Required and recommended texts, Required and provided materials, Attire), Course plan (Lecture and/or lab topics, Landmark events, assessments, and due dates, Last course revision date), How learning will be assessed (Grading procedure, Grading scale and method, Missed assessments, Grade posting, Results of a failing grade), Technical, classroom, and college policy information (Syllabus amendments, Special needs, Student conduct and class/college policies). Altman and Cashin (1992) presents guidelines for writing a syllabus for college courses for both experienced and novice teachers. The purpose of the syllabus in communicating course content, purpose, direction and requirements is discussed, as is the necessity of planning the course before syllabus writing. Major content areas of the syllabus are reviewed, including course and instructor information, texts and materials, course objectives, calendar and policies, attendance, class participation, grading, honour policy, and available support services.

\section{DEPARTMENT OF INDUSTRIAL ENGINEERING AT KAU}

The Faculty of Engineering at King Abdulaziz University (2016) was ranked 112 out of hundreds of colleges by the Shanghai Academic Rankings of World Universities in engineering technology and computer sciences in 2013. The Faculty consists of eight departments, offering fourteen undergraduate and graduate degree programs. All the undergraduate programs are accredited by the Accreditation Board for Engineering and Technology (ABET), which is recognized by the Council for Higher Education Accreditation (CHEA). KAU Engineering is also a proud ISO 9001 certified institution, demonstrating its organizational quality management and international standards driven efficiency towards continuous development.

The Faculty has an average of 2,100 enrolled students, more than 220 faculty members, over 75 labs, various centers of excellence, and numerous academic support programs. Faculty of Engineering optimizes its close relations with highly recognized academic institutions and industries by providing a wealth of resources and career boosting options for its engineering alumni, who experience an $80 \%$ employment rate within six months of graduation on average.

The eight Departments in the Faculty of engineering are: Aeronautical Engineering, Chemical and Materials Engineering, Civil Engineering, Electrical and Computer Engineering, Industrial Engineering, Mechanical Engineering, Mining Engineering and Nuclear Engineering.

The Faculty of Engineering offers a Bachelor's Degree in 14 programs. The Chemical and Materials Engineering Department offers only one BS program, namely Chemical Engineering. In that department the 'Materials Engineering' track is applicable only for the MS program. The Electrical Engineering Department, on the other hand, offers four BS programs. There are two BS programs in the Mechanical Engineering Department, while the Nuclear Engineering Department offers three programs

The Department of Industrial Engineering (IE) at King Abdulaziz University (KAU) was established in $1395 \mathrm{H}$ (1975 G) thus becoming a pioneer in IE education and training in the Kingdom of Saudi Arabia (KSA). Since then IE graduates are working in various technical or managerial positions that include manufacturing industry, banks, hospitals, transportation companies, communications, and defense industries.

Industrial Engineering (IE) is a branch of engineering which deals with design, development, implementation, and improvement of integrated systems that include people, materials, information, equipment and energy. It is thus unique as compared to other branches of engineering in the sense that it deals not only with inanimate objects but also with the behaviour of human beings in relation to these objects. For this purpose, it draws heavily on mathematical, physical, information and social sciences, and other engineering principles 
of system analysis and design.

The demand of industrial engineers in KSA is increasing since the pace of development is very fast, there is considerable scope for improvement in different aspects of working in almost every organization and due to the fact that the Kingdom is short of manpower.

The IE program offers a 5-year study program leading to a Bachelor of Science degree (B. Sc.) in Industrial Engineering and covers five very important areas of the industry: Operations Research, Information Systems, Stochastic Processes, Human Factors Engineering and Engineering Management.

The area of Operations Research includes 2 core courses (Operations research I and II) and three elective ones: Decision Analysis, Network Analysis, and Project Management. A Teaching Activities Focus Team (TAFT) is formed to redesign courses for the Operations Research Group in the Department, several constraints should be taken into considerations as illustrated in Figure 2.

University and Faculty Required Courses [77 Credit Units (CU)]: Foundation Year (27 CU), ISLS (Islamic Courses) (8 CU), ARAB (6 CU), Free Elective Courses (6 CU), and Faculty Required Courses (30 CU). Program Required Courses [78 CU]: Mandatory Courses (40-45\% - 62-70 CU) and Elective Courses (8-15\% - 12-23 CU).

Accreditation (ABET) Requirements: Math and Science Courses (32 CU), Engineering Courses (48 CU), Program Criteria Courses, Student Outcomes (Old vs. New), Major Design Experience (Capstone Design Project - 1/2 courses), Use of Engineering Standards (Availability) and should Include a business element in the curriculum (2016 Symposium).

Fundamental Engineering (FE) Exam Requirements: Linear programming: (Formulation, Graphical solution), Optimization modelling (e.g., decision variables, objective functions, and constraints), Primal Dual Linear Program, Transportation Problem, Assignment Problem, Integer Programming, Network Optimization, Queueing Models: Definitions, Kendall notation for describing a queueing system, Fundamental Relationships, Single Server Models ( $s=1)$, Multiple Server Model $(s>1)$, Inventory Models: Economic order quantity, Dynamic Programming, Markov Analysis, Critical Path Method (CPM), PERT, Reliability, Decision theory (e.g., uncertainty, risk, utility, decision trees).

Benchmark: Best practices are a set of guidelines that represent the most efficient course of action. A best practice is a technique or methodology that, through experience and research, has proven to reliably lead to a desired result. It is a method or technique that has consistently shown results superior to those achieved with other means, and that is used as a benchmark. The Top 10 Universities are used as benchmarks for enhancing the courses and syllabi, these universities are: Georgia Institute of Technology (GIT), University of Michigan--Ann Arbor (UM), Purdue University (PU), University of California-Berkeley (UC), Northwestern University (McCormick) (NU), Stanford University (SU), Virginia Tech (VT), Pennsylvania State University (PSU), University of Wisconsin-Madison (UMW), and Cornell University (CU).

Job Market Needs: The job market is the market in which employers search for employees and employees search for jobs. The job market is not a concept demonstrating the competition and interplay between different labor forces. The job market can grow or shrink depending on the labor demand and supply within the overall economy, specific industries, for specific education levels or specific job functions.

\section{BENCHMARK-TOP TEN U.S. UNIVERSITIES}

Best practices are a set of guidelines, ethics or ideas that represent the most efficient or prudent course of action. Best practices are often set forth by an authority, such as a governing body or management, depending on the circumstances. While best practices generally dictate the recommended course of action, some situations require that such practices be followed. A best practice is a technique or methodology that, through experience and research, has proven to reliably lead to a desired result. A commitment to using the best practices in any field is a commitment to using all the knowledge and technology at one's disposal to ensure success. It is a method or technique that has consistently shown results superior to those achieved with other means, and that is used as a benchmark.

A benchmark is a standard, or a set of standards, used as a point of reference for evaluating performance or level of quality. Benchmarks may be drawn from a firm's own experience, from the experience of other firms in the industry, or from legal requirements such as environmental regulations. The top 10 U.S. universities practices will be used as a suitable benchmark for the courses and course Syllabi assessment for the Department of Industrial Engineering and mainly for the Operations Research Group. 


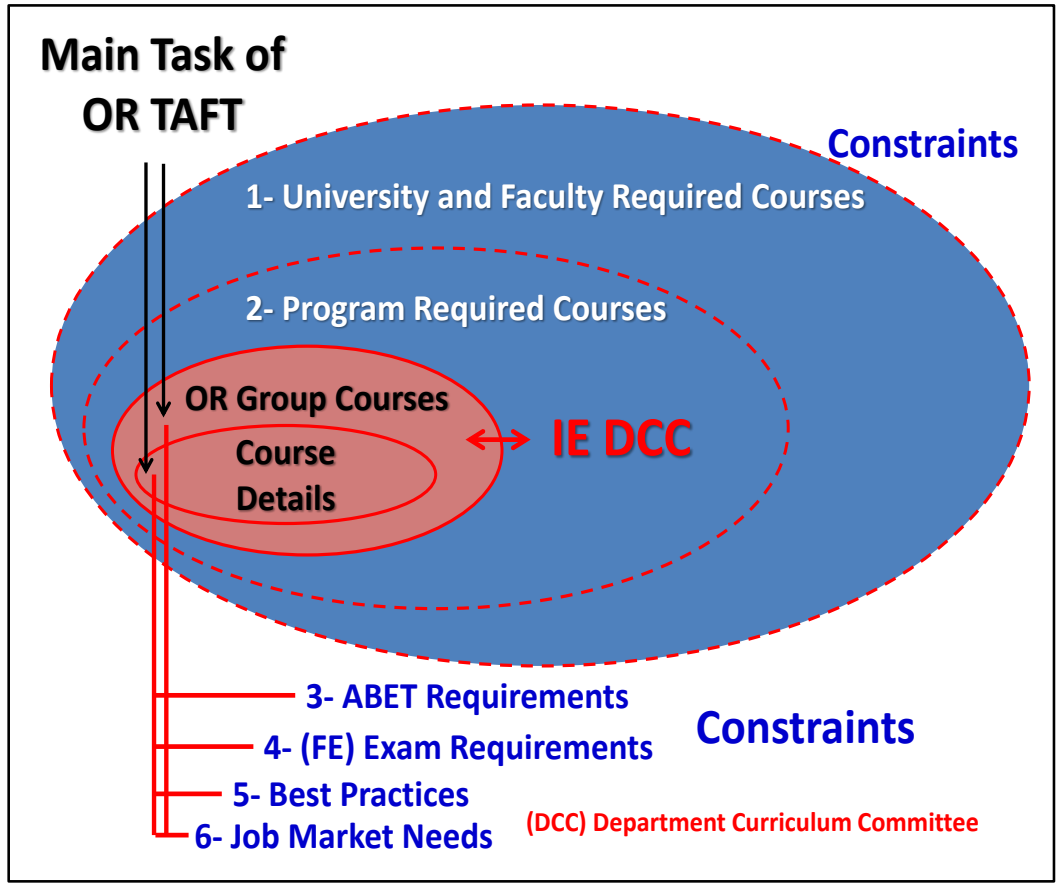

Figure 2: Operations Research TAFT tasks and constraints.

The Top Ten U.S. Universities are (US News Education. Industrial / Manufacturing Rankings, 2016):

1. Georgia Institute of Technology (GIT),

3. Purdue University (PU),

5. Northwestern University (McCormick) (NU)

7. Virginia Tech (VT)

9. University of Wisconsin-Madison (UMW)
2. University of Michigan--Ann Arbor (UM)

4. University of California-Berkeley (UC),

6. Stanford University (SU)

8. Pennsylvania State University (PSU)

10. Cornell University (CU)

Table 1 presents matching between OR Group courses and the relevant courses in the top ten Universities, and Table 2 presents a part of a table matching between Network Analysis course contents and the top Ten U.S. Universities.

Table 1: Matching between courses in the OR Group and the top ten Universities.

\begin{tabular}{|l|c|c|c|c|c|c|c|c|c|c|}
\hline \multirow{2}{*}{ OR Group Courses } & \multicolumn{7}{|c|}{ Top IE $\mathbf{1 0}$ U.S. Universities } \\
\hline & $\mathbf{1}$ & $\mathbf{2}$ & $\mathbf{3}$ & $\mathbf{4}$ & $\mathbf{5}$ & $\mathbf{6}$ & $\mathbf{7}$ & $\mathbf{8}$ & $\mathbf{9}$ & $\mathbf{1 0}$ \\
\hline Operations Research I & $\sqrt{ }$ & $\sqrt{ }$ & $\sqrt{ }$ & $\sqrt{ }$ & $\sqrt{ }$ & $\sqrt{ }$ & $\sqrt{ }$ & $\sqrt{ }$ & $\sqrt{ }$ & $\sqrt{ }$ \\
\hline Operations Research II & $\sqrt{ }$ & $\sqrt{ }$ & $\sqrt{ }$ & $\sqrt{ }$ & $\sqrt{ }$ & $\sqrt{ }$ & $\sqrt{ }$ & $\sqrt{ }$ & & $\sqrt{ }$ \\
\hline Decision Analysis & & $\sqrt{ }$ & $\sqrt{ }$ & $\sqrt{ }$ & & $\sqrt{ }$ & & & $\sqrt{ }$ & \\
\hline Network Analysis & & & & $\sqrt{ }$ & & $\sqrt{ }$ & & & $\sqrt{ }$ & \\
\hline Project Management & & & & & & & $\sqrt{ }$ & & & \\
\hline
\end{tabular}


Table 2: Matching the Network Analysis course contents with the top ten Universities.

\begin{tabular}{|l|l|l|l|l|l|l|l|l|l|l|}
\hline \multirow{2}{*}{ Network Analysis contents (IE413) } & \multicolumn{7}{|c|}{ Top IE 10 U.S. Universities } \\
\hline & $\mathbf{1}$ & $\mathbf{2}$ & $\mathbf{3}$ & $\mathbf{4}$ & $\mathbf{5}$ & $\mathbf{6}$ & $\mathbf{7}$ & $\mathbf{8}$ & $\mathbf{9}$ & $\mathbf{1 0}$ \\
\hline Introduction to network analysis with industrial applications & & & & $\sqrt{ }$ & & & & & & \\
\hline Systems modelling and analysis using network techniques & & & $\sqrt{ }$ & & $\sqrt{ }$ & $\sqrt{ }$ & $\sqrt{ }$ & $\sqrt{ }$ & $\sqrt{ }$ & \\
\hline CPM with LP formulation & & & & $\sqrt{ }$ & & & & & & \\
\hline PERT with LP formulation and cost analysis & & & & & & & & & & \\
\hline Other network algorithms: Minimum spanning tree & & & & $\sqrt{ }$ & $\sqrt{ }$ & $\sqrt{ }$ & $\sqrt{ }$ & & & \\
\hline Shortest path & & & & $\sqrt{ }$ & $\sqrt{ }$ & $\sqrt{ }$ & $\sqrt{ }$ & & $\sqrt{ }$ & \\
\hline Maximal flow problem & & & & $\sqrt{ }$ & $\sqrt{ }$ & & & & $\sqrt{ }$ & \\
\hline Flow graph theory & & & & & & & & & & \\
\hline GERT: exclusive OR networks & & & & & & & & & \\
\hline
\end{tabular}

\section{THE FUNDAMENTAL OF ENGINEERING (FE) EXAM}

The Fundamentals of Engineering (FE) exam is typically the first step in the process leading to the Professional Engineering (P.E.) license. It is designed for recent graduates and students who are close to finishing an undergraduate engineering degree. The Fundamentals of Engineering (FE) exam, also referred to as the Engineer in Training (EIT) exam, is the first of two examinations that engineers must pass in order to be licensed as a Professional Engineer in the United States. The exam is open to anyone with a degree in engineering or a related field, or currently enrolled in the last year of an ABET-accredited engineering degree program. Some state licensure boards permit students to take it prior to their final year, and numerous states allow those who have never attended an approved program to take the exam if they have a state-determined number of years of work experience in engineering. The exam is administered by the National Council of Examiners for Engineering and Surveying (NCEES).

The FE is a computer-based exam that is administered year-round at the National Council of Examiners for Engineering and Surveying (2016) (NCEES)-approved Pearson VUE test centers.

The FE contains 110 multiple-choice questions. The exam appointment time is 6 hours long, which includes a nondisclosure agreement, tutorial (8 minutes), the exam (5 hours and 20 minutes), and a scheduled break (25 minutes). The FE is offered in seven disciplines. Specifications for the exams are as follows: Chemical, Civil, Electrical and Computer, Environmental, Industrial and Systems, Mechanical, and Other Disciplines.

The Fundamentals of Engineering Examination is an six-hour exam with a supplied reference manual. No other books or notes or blank paper is permitted in the testing area.

The contents of the NCEES Reference Handbook (2015) are: Units, Conversion Factors, Ethics, Safety, Mathematics, Engineering Probability and Statistics, Chemistry, Materials Science/Structure of Matter, Statics, Dynamics, Mechanics of Materials, Thermodynamics, Fluid Mechanics, Heat Transfer, Instrumentation, Measurement, and Controls, Engineering Economics, Chemical Engineering, Civil Engineering, Environmental Engineering, Electrical and Computer Engineering, Industrial Engineering, Mechanical Engineering, FE Exam Specifications.

The Industrial Engineering contents as stated in NCEES (2015) are as follows:

1. Optimization modelling (e.g., decision variables, objective functions, and constraints),

2. Linear programming: (Formulation, Graphical solution), Primal Dual Linear Program,

3. Transportation Problem,

4. Assignment Problem,

5. Integer Programming

6. Network Optimization,

7. Queueing Models: Definitions, Kendall notation for describing a queueing system, Fundamental Relationships, Single Server Models $(s=1)$, Multiple Server Model $(s>1)$,

8. Inventory Models: Economic order quantity, 
9. Dynamic Programming,

10. Markov Analysis,

11. Project management (e.g., scheduling, PERT, CPM),

12. Reliability, and

13. Decision theory (e.g., uncertainty, risk, utility, decision trees).

Table 3 presents a part of a table matching between the FE topics for OR Group and OR group courses for the core course Operations Research II, other courses are also considered.

\section{FACULTY EXPERIENCE}

OR TAFT are 18 Faculty members, they are asked to fill a questionnaire to indicate topics to be deleted, titles of topics to be added, and to agree about the used text book or to propose a new one. Table 4 shows a part of the questionnaire for one course; other courses in the group are also included. The feedback is used for enhancing the course contents and the used textbooks.

\section{CONCLUSIONS AND POINTS FOR FUTURE RESEARCHES}

\subsection{Conclusions}

An assessment procedure for Industrial Engineering courses related to the Operations research Group is introduced. The process is an iterative one for considering the used attributes of assessing. The attributes are: the benchmark Universities, the Fundamental Engineering Exam requirements, and the Faculty experience. Two core and three elective courses are considered in the study.

The assessment process regarding the FE Exam requirements reveals that all topics in FE Modelling section are covered except one topic (Reliability); this topic is also listed in the FE Probability and Statistic section and is recommended to be covered in that TAFT group. Since many topics in FE Modelling section are covered in elective courses (Decision Analysis and Network Analysis), it is recommended to advise students to register these two elective courses while giving lower priority to register for the third elective course (Project management).

The questionnaire responses of the faculty members recommend some minor transitions and changes in some course contents by very few members, and in the recommendation to change some of the used text books to new ones either because of old versions or because they believe they are better.

The benchmark and comparison with the top Ten Universities reveals that similar courses to the two core courses Operations Research I and II exist in almost all the top ten Universities. Similar courses to the course Decision Analysis exist in half of the top Ten Universities. Similar courses to the course Network Analysis exist only in three universities and the course Project Management exists only in one University. The detailed topics for the courses are also assessed; some topics are common in most of the Universities, while some others are rarely mentioned or not included at all.

The comprehensive results obtained from the benchmark Universities, the Fundamental Engineering Exam requirements, and the Faculty experience are used to enhance the courses and course contents in the Operations Research Group.

\subsection{Points for Future Researches}

These points are raised as direction for future researches:

- To apply the recommendations for course and syllabus enhancements, and to measure the output and feedback for further assessment and enhancements.

- To include other assessment criteria like: the vision and mission of the IE Department, Accreditation (like) ABET Requirements, Job Market Needs and Teaching tools in the development process.

- To extend this research to include all the IE Program courses and curricula.

- To apply the same procedure for other Programs in the Faculty of Engineering at King Abdulaziz University. 
Table 3: Matching between FE topics and ORII course.

\begin{tabular}{|l|l|l|l|l|l|l|l|l|l|l|l|l|l|}
\hline \multirow{2}{*}{ OR Group Courses } & \multicolumn{8}{|c|}{ FE Topics for OR Group } \\
\hline & $\mathbf{1}$ & $\mathbf{2}$ & $\mathbf{3}$ & $\mathbf{4}$ & $\mathbf{5}$ & $\mathbf{6}$ & $\mathbf{7}$ & $\mathbf{8}$ & $\mathbf{9}$ & $\mathbf{1 0}$ & $\mathbf{1 1}$ & $\mathbf{1 2}$ & $\mathbf{1 3}$ \\
\hline Operations Research II: & & & & & & & & & & & & & \\
\hline Non-linear programming & & & & & & & & & & & & & \\
\hline Dynamic programming & & & & & & & & & $\sqrt{ }$ & & & & \\
\hline Inventory models & & & & & & & & $\sqrt{ }$ & & & & & \\
\hline Waiting line (Queueing) models & & & & & & & $\sqrt{ }$ & & & & & & \\
\hline Markov analysis & & & & & & & & & & $\sqrt{ }$ & & & \\
\hline
\end{tabular}

Table 4: Contents of the questionnaire for the faculty members.

\begin{tabular}{|c|c|c|}
\hline Course: & 1 & 2. Topics to be added \\
\hline IE 311-Operations Research I (Core): & & \\
\hline Introduction to OR & & \\
\hline Formulation of LP problems & & \\
\hline Graphical solution & & \\
\hline Simplex algorithm & & \\
\hline Duality analysis & & \\
\hline Sensitivity analysis & & \\
\hline Transportation problems & & \\
\hline Assignment problems & & \\
\hline Integer programming & & \\
\hline Zero-One programming & & \\
\hline Goal programming & & \\
\hline The Current Text Book: & & New Proposed Book: \\
\hline $\begin{array}{l}\text { Quantitative Analysis for Management, Barry } \\
\text { Render, Ralph M. Stair (Jr) and Michael } \\
\text { Henna, Prentice Hall International Inc., 12th } \\
\text { Edition (2015). }\end{array}$ & & \\
\hline
\end{tabular}

\section{ACKNOWLEDGMENT}

The authors would like to acknowledge the valuable inputs provided by the Operations Research Group members in the Department of Industrial Engineering at King Abdulaziz University. Special thanks to the Chairman of the Department and to the Curriculum Committee at the Faculty of Engineering.

\section{REFERENCE LIST}

Altman, H.B., and Cashin, W.E. (1992). Writing a syllabus, Report No. HE 029 193, Manhattan, KS: Kansas State University, Manhattan Center for Faculty Evaluation and Development in Higher Education; IDEA paper No. 27, ERIC Document Reproduction Service No. ED 395539.

Ariovich, L. and Walker, S. A. (2015), Assessing Course Redesign: The Case of Developmental Math, 
Research \& Practice in Assessment, pp. 54:57. Available at:http://www.rpajournal.com/dev/wpcontent/uploads/2014/06/A3.pdf

Bogan, C.E. and English, M.J. (1994). Bench marking for Best Practices: Winning Through Innovative Adaptation. New York: McGraw-Hill.

Cusson, M., (2015), Moving towards an outcomes-based curriculum, Academic Quality Assurance, Degree Level Expectations, Educational Development Centre. Available at: http://carleton.ca/viceprovost/wpcontent/uploads/Degree-Level-Expectations-March-2012.pdf

Diamond R.M. (1998). Designing and assessing courses and curricula: a practical guide. San Francisco: Jossey-Bass; 1998. pp. 191-202.

Dubin, F. \& Olshtain, E. (1997). Course Design: Developing Programs and Materials for Language Learning, Cambridge: Cambridge University Press.

Gosling, D. (2009) Learning Outcomes Debate. Accessed 12th Sept, 2009 http://www.davidgosling.net/userfiles/Learning\%200utcomes\%20Debate(1).pdf

Grunert J. (1997). The course syllabus: a learning-centered approach. Boston: Anker Publishing Co.

Habanek, D.V. (2005). An examination of the integrity of the syllabus. Col Teach. 2005; 53:62-4.

Hussey, T. \& Smith, P (2003) The Uses of Learning Outcomes. Teaching in Higher Education, Vol. 8, No. 3, 2003, pp. 357-368

Hussey, T, \& Smith, P. (2008) Learning Outcomes: A Conceptual Analysis. Teaching in Higher Education. 13 (1), 107-115.

Hutchinson, T. \& Waters, A (1996). ESP A learning centered approach. Great Britain Cambridge University Press.

Johnson, C. (2006). Best Practices in Syllabus Writing, Contents of a Learner-Centered Syllabus, Journal Chiropractic Education, Fall; 20(2): 139-144.

Maher, A. (2004) Learning Outcomes in Higher Education: Implications for Curriculum Design and Student Learning. Journal of Hospitality, Leisure, Sport and Tourism Education. 3 (2) 46-54.

McKimm, J., (2003), Curriculum design and development, School of Medicine, Imperial College Centre for Educational Development. Available at:http://www.faculty.londondeanery.ac.uk/e-learning/settinglearning-objectives/Curriculum_design_and_development.pdf

Moreno, P. (2000) The Implications of Curriculum Design for a Graduate of the English Language Program at Universidad Veracruzana. Unpublished dissertation. Mexico.

National Council of Examiners for Engineering and Surveying (2016) website, visited at 9 April 2016. Available at: http://ncees.org/exams/fe-exam/

NCEES Reference Handbook (2015), United States of America, Third printing, June 2015, Edition 9.3, ISBN 978-1-932613-67-4. Available at:https://cdn.ncees.org/wpcontent/uploads/2012/11/FE_REFERENCE_9_3_WEB.pdf

NCEES website (2016). Visited on 20 April 2016. Available at: http://ncees.org/about-ncees/

Neary, M. (2003). Curriculum concepts and research. In Curriculum studies in post-compulsory and adult education: A teacher's and student teacher's study guide. (pp33-56). Cheltenham: Nelson Thornes Ltd.

Nulty, D. D., (2012), Curriculum Design, Griffith Institute for Higher Education. Available at: https://www.griffith.edu.au/_data/assets/pdf_file/0004/437350/Curriculum-Design-Learning

Nunan, D. (2000 ) Syllabus Design, Oxford: Oxford University Press.

Ornstein A.C. \& Hunkins, F.P. (2009). Curriculum foundations, principles and issues. (5th ed). Boston: Allyn and Bacon.

Parkes J., Fix. .K., and Harris, M.B. (2003). What syllabi communicate about assessment in college classrooms, J. Excell Col Teach. 2003; 14:61-83.

Richards, J. (2001) Curriculum Development in Language Teaching, Cambridge: Cambridge University 
Press.

Richards, Platt and Platt (1993). Dictionary of Language Teaching \& Applied Linguistics. London: Longman.

The Center for teaching and Learning (2004), Designing courses, Speaking of Teaching, , Stanford University, Winters 2004 Newsletter, Vol. 13, No. 2. Available at:

http://web.stanford.edu/dept/CTL/Newsletter/designing_courses.pdf

The Faculty of Engineering at King Abdulaziz University (2016). Visited on 9 April 2016. Available at: http://engineering.kau.edu.sa/Default.aspx?Site_ID=135\&Lng=EN

The National center for Academic Reformation, (2016), Six Models for Course Redesign. Visited on 6 April 2016. Available at: http://www.thencat.org/PlanRes/R2R_ModCrsRed.htm Objectives-andOutcomes.pdf

Twigg, C. A., (2015), An overview of course redesign, National Center for Academic Transformation. Available at: http://www.thencat.org/Articles/An\%20Overview\%20of\%20Course\%20Redesign.pdf

US News Education. Industrial / Manufacturing Rankings (2016). Visited on 20 April 2016. Available at: http://colleges.usnews.rankingsandreviews.com/best-colleges/rankings/engineering-doctorateindustrial-manufacturing

White, R. (1993) The ELT Curriculum, USA: Cambridge University Press.

Woolcock, M. J.V., (2005), Constructing a Syllabus, The Harriet W. Sheridan Center for Teaching and Learning, Brown University. 